\title{
Contribution of iron and $A \beta$ to age differences in entorhinal and hippocampal subfield volume
}

Chris M. Foster, PhD, Kristen M. Kennedy, PhD, Ana M. Daugherty, PhD, and Karen M. Rodrigue, PhD

Neurology ${ }^{\circledR}$ 2020;95:e2586-e2594. doi:10.1212/WNL.0000000000010868

\section{Abstract}

\section{Objective}

To test the hypothesis that the combination of elevated global $\beta$-AMYLOID (A $\beta$ ) burden and greater striatal iron content would be associated with smaller entorhinal cortex (ERC) volume, but not hippocampal subfield volumes, we measured volume and iron content using highresolution $\mathrm{MRI}$ and $\mathrm{A} \beta$ using $\mathrm{PET}$ imaging in a cross-sectional sample of 70 cognitively normal older adults.

\section{Methods}

Participants were scanned with florbetapir ${ }^{18} \mathrm{~F}$ PET to obtain $\mathrm{A} \beta$ standardized uptake value ratios. Susceptibility-weighted MRI was collected and processed to yield R2* images, and striatal regions of interest (ROIs) were manually placed to obtain a measure of striatal iron burden. Ultra-high resolution T2/PD-weighted MRIs were segmented to measure medial temporal lobe (MTL) volumes. Analyses were conducted using mixed-effects models with MTL ROI as a within-participant factor; age, iron content, and A $\beta$ as between-participant factors; and MTL volumes (ERC and 3 hippocampal subfield regions) as the dependent variable.

\section{Results}

The model indicated a significant 4-way interaction among age, iron, $A \beta$, and MTL region. Post hoc analyses indicated that the 3-way interaction among age, $\mathrm{A} \beta$, and iron content was selective to the ERC ( $\beta=-3.34$, standard error $=1.33$, 95\% confidence interval -5.95 to -0.72$)$, whereas a significant negative association between age and ERC volume was present only in individuals with both elevated iron content and $\mathrm{A} \beta$.

\section{Conclusions}

These findings highlight the importance of studying $A \beta$ in the context of other, potentially synergistic age-related brain factors such as iron accumulation and the potential role for iron as an important contributor to the earliest, preclinical stages of pathologic aging.

\author{
Correspondence \\ Dr. Rodrigue \\ krodrigue@utdallas.edu
}

\section{RELATED ARTICLE}

Editorial

Early role of iron in modulating amyloid's association with neurodegeneration

Page 809

From the School of Behavioral and Brain Sciences (C.M.F., K.M.K., K.M.R.), Center for Vital Longevity, University of Texas at Dallas; and Department of Psychology (A.M.D.) and Department of Psychiatry and Behavioral Neurosciences, Institute of Gerontology, Wayne State University, Detroit, MI.

Go to Neurology.org/N for full disclosures. Funding information and disclosures deemed relevant by the authors, if any, are provided at the end of the article. 


\section{Glossary}

$\mathbf{A} \beta=\beta$-amyloid $\mathbf{A D}=$ Alzheimer disease; $\mathbf{C A 1} / \mathbf{2}=$ cornu ammonis 1-2; CA3 $/ \mathbf{D G}=$ cornu ammonis 3/dentate gyrus; $\mathbf{C I}=$ confidence interval; ERC = entorhinal cortex; FDR = false discovery rate; $\mathbf{M T L}=$ medial temporal lobe; $\mathbf{R}^{*}=$ striatal nonheme iron content; ROI = region of interest; SUVR = standardized uptake value ratio.

$\beta$-Amyloid $(\mathrm{A} \beta)$ accumulation may be the earliest in vivo biomarker of Alzheimer disease $(\mathrm{AD}){ }^{1,2}$ yet the deleterious effects of $A \beta$ on the brain have been difficult to establish. ${ }^{3} A$ prevalent hypothesis suggests that excessive $A \beta$ promotes oxidative stress. ${ }^{3,4}$ Brain iron accumulation is a proxy indicator of oxidative stress that may shed some light on the effect of $A \beta$ on the brain. In the course of aging, nonheme iron accumulates outside of binding complexes and promotes oxidative stress. ${ }^{5-8}$ A disruption of iron homeostasis is also thought to play a significant role in the conversion of normal $A \beta$ monomers into toxic $\mathrm{A} \beta$ oligomers and plaques, ${ }^{5,9}$ and some evidence suggests that nonheme iron exacerbates the toxicity of $\mathrm{A} \beta$ to a variety of cellular membranes. ${ }^{10}$

The entorhinal cortex (ERC) is a target of early $\mathrm{AD}$-related pathology ${ }^{11,12}$ and may exhibit structural changes associated with oxidative stress early in the disease cascade. Notably, compared to volumes of the hippocampus and its subfields, ERC volumes in nonpathologic aging are relatively stable across the adult lifespan. ${ }^{13,14}$ Volumetric differences in the ERC may therefore be indicative of accelerated cognitive aging $^{15}$ or represent underlying $\mathrm{AD}$-related changes. ${ }^{12,16}$

The current study aimed to assess associations among early markers of $\mathrm{AD}, \mathrm{A} \beta$, and brain iron content with $\mathrm{ERC}$ and hippocampal subfield volumes in cognitively normal older adults. We hypothesized that (1) striatal brain iron content would be positively associated with $A \beta$ burden and (2) elevated $A \beta$ burden and striatal iron content, but not hippocampal subfield volumes, would be related to smaller ERC volume in older adults.

\section{Methods}

\section{Standard protocol approvals, registrations, and patient consents}

This study was approved by the University of Texas at Dallas and the University of Texas Southwestern Medical Center Institutional Review Boards. Written informed consent was obtained from all participants.

\section{Participants}

Seventy participants (mean age 68.29 years, SD 10.48 years, range 51-94 years) with complete PET and MRI data were drawn from a larger sample of individuals recruited from the Dallas-Fort Worth metroplex with data collection occurring between 2013 and 2016. All participants in the current analysis underwent cognitive testing consisting primarily of standardized neuropsychological instruments, as well as MRI and PET scanning. Participants were all right-handed; native English speakers; screened to be free from a history of neurologic, cardiovascular, psychiatric, or metabolic disorders, substance abuse, or head injuries with a loss of consciousness $>5$ minutes; and required to score $\geq 26$ on the Mini-Mental State Examination ${ }^{17}$ and $\leq 16$ on the Center for Epidemiologic Study-Depression. ${ }^{18}$ Participants were required to be $\geq 50$ years of age to participate in PET imaging. Thirty-six eligible participants from the larger sample did not complete PET imaging. Those individuals were not significantly different on any demographic variable-age (mean $66.42,95 \%$ confidence interval [CI] 62.95-69.88), Center for Epidemiologic Study-Depression score (mean 4.81, 95\% CI 3.48-6.13), education (mean 15.22 years, 95\% CI 14.29-16.16), MiniMental State Examination score (mean 28.67, 95\% CI 28.38-28.96) - from the 70 included in the current analysis. Table 1 provides sample demographic information.

\section{Neuroimaging protocol}

\section{MRI acquisition}

MRIs were collected at the University of Texas Southwestern Medical Center's Advanced Imaging Research Center on a single 3T Philips Achieva whole-body scanner (Philips Medical Systems, Andover, MA) equipped with a 32-channel head coil. Regional iron content was assessed with a $\mathrm{T} 2{ }^{*}$ weighted multiecho 3D gradient-recalled echo sequence $(65$ axial slices, 8 echo times 5.68 milliseconds $+\Delta 2.57$ milliseconds, flip angle $15^{\circ}$, repetition time 37 milliseconds, field of view $256 \mathrm{~mm}^{2}, 512 \times 512 \times 65$ matrix, voxel size $0.5 \times 0.5 \times$ $2 \mathrm{~mm}^{3}$, total time 10:14 minutes). Regional medial temporal lobe (MTL) volumes were assessed from an ultrahighresolution T2/PD-weighted image of the MTL aligned along the longitudinal axis of the hippocampus (repetition time 3,500 milliseconds, echo time 44 milliseconds, field of view $215 \times 215 \mathrm{~mm}$, voxel size $0.42 \times 0.42 \times 2.00 \mathrm{~mm}^{3}, 30$ coronal slices, flip angle $120^{\circ}$, total time $6: 46$ minutes) and facilitated by collection of a T1-weighted high-resolution magnetizationprepared rapid acquisition with gradient echo sequence (repetition time 8.3 milliseconds, echo time 3.8 milliseconds, field of view $256 \times 204 \mathrm{~mm}$, voxel size $1 \times 1 \times 1 \mathrm{~mm}^{3}, 160$ sagittal slices, flip angle $12^{\circ}$, total time $3: 57$ minutes).

\section{Iron content processing}

The $\mathrm{T}^{*}$-weighted gradient-recalled echo images were processed to produce $\mathrm{R} 2{ }^{*}$ images (a measure of striatal nonheme iron content) according to a pipeline used in our prior reports. ${ }^{19,20}$ Images were processed and masked in the Signal Processing in NMR software package (SPIN; MR Innovations, Inc, Detroit, MI; mrinnovations.com/spin-lite; last 
Table 1 Demographics and summary statistics

\begin{tabular}{|c|c|c|c|}
\hline Demographics & Mean (SD) & Minimum & Maximum \\
\hline Age, y & $68.29(10.48)$ & 51 & 94 \\
\hline Female, $\%$ & 60.00 & & \\
\hline Education, y & $15.59(2.60)$ & 12 & 20 \\
\hline CESD score & 3.84 (3.65) & 0 & 16 \\
\hline MMSE score & $28.83(0.76)$ & 26 & 30 \\
\hline \multicolumn{4}{|l|}{ Volume, $\mathrm{mm}^{3}$} \\
\hline ERC & $517.78(87.10)$ & 324.93 & 858.72 \\
\hline Subiculum & $549.01(69.48)$ & 396.90 & 693.61 \\
\hline CA1/2 & 310.05 (40.39) & 179.93 & 404.31 \\
\hline CA3/DG & $445.49(64.36)$ & 304.47 & 633.63 \\
\hline \multicolumn{4}{|l|}{$A \beta$ and iron } \\
\hline SUVR & $1.11(0.16)$ & 0.93 & 1.66 \\
\hline $\mathrm{R} 2 *, \mathrm{~s}^{-1}$ & $30.78(6.72)$ & 20.23 & 54.56 \\
\hline
\end{tabular}

Abbreviations: $A \beta=\beta$-amyloid; $C A=$ cornu ammonis; $C E S D=$ Center for $E p$ idemiologic Study-Depression; DG = dentate gyrus; ERC = entorhinal cortex; MMSE = Mini-Mental State Examination; R2* = measure of striatal nonheme iron content; SUVR = A $\beta$ standardized uptake value ratio.

accessed March 29, 2019). R2*, for which higher-intensity values indicate relatively greater iron concentration, was calculated as the inverse of $\mathrm{T} 2{ }^{*}$ at each voxel. Circular masks ( 24 pixels each) were manually placed within the bilateral caudate nucleus and putamen to estimate iron content (figure 1). Four masks were placed on a single image slice within each region per hemisphere, and this was continued for 3 contiguous slices (see reference 19 for detailed procedure). Masks were placed by a single individual (C.M., who was trained by A.M.D.). Reliability was assessed with intraclass correlation coefficient (2) using a sample of 10 participants. ${ }^{21}$ In the reported analyses, iron estimates were averaged across the regions of interest (ROIs) to calculate a single estimate of striatal iron content. The striatum accumulates iron across the lifespan and is sensitive to disruption of whole-brain iron homeostasis $^{22,23}$; therefore, the measurement was used here as an indicator of general age-related risk for oxidative stress in the brain.

\section{MTL volumes}

Volumes for the 4 MTL ROIs, including the ERC, subiculum, cornu ammonis 1-2 (CA1/2), and cornu ammonis 3/dentate gyrus (CA3/DG), were estimated with a semiautomated pipeline (see reference 24 for detailed procedure). Manual tracings of MTL ROIs were completed for 30 participants across the lifespan of the entire sample using recommendations from the hippocampal subfield harmonization workgroup. ${ }^{25}$ The Automatic Segmentation of Hippocampal Subfields version 1.0.0 software was then used to create a study-specific atlas and to apply machine-learning algorithms to segment all subfields for all the participants. ${ }^{26}$ All MTL ROI volumes were summed across hemispheres and adjusted for intracranial volume using the analysis of covariance approach. ${ }^{27}$

\section{PET acquisition}

PET scans were collected on a Siemens ECAT HR PET scanner (Siemens, Malvern, PA) housed at UT Southwestern Medical School. Participants were injected with $370 \mathrm{MBq}(10$ $\mathrm{mCi}$ ) of ${ }^{18} \mathrm{~F}$-florbetapir (Avid Radiopharmaceuticals/Eli Lilly, Indianapolis, IN). Approximately 30 minutes after injection, participants were placed on the imaging table. A 2-minute scout was acquired to ensure that the brain was within the field of view. Fifty minutes after injection, an internal rod source transmission scan was acquired for 7 minutes, followed immediately by a dynamic emission acquisition of 2 frames by 5 minutes each. The transmission image was reconstructed using back-projection with a 6-mm full width at halfmaximum gaussian filter. Emission images were processed by iterative reconstruction, 4 iterations and 16 subsets with a 3-mm full width at half-maximum ramp filter.

\section{PET processing}

Each participant's PET scan was first registered to the T1weighted image with a rigid registration followed by an affine registration using Advanced Normalization Tools ${ }^{28}$ scripts and visually inspected for registration quality. FreeSurfer version $5.3^{29}$ parcellations of interest that correspond to the traditionally used 7 ROIs for amyloid deposition (i.e., anterior cingulate, posterior cingulate, precuneus, lateral temporal, lateral parietal, middle frontal, and inferior frontal) were also registered to each participant's T1 image. Using methods outlined elsewhere, ${ }^{30}$ we extracted uptake counts from each ROI, normalized them to whole cerebellar counts to yield standardized uptake value ratios (SUVRs) for each ROI, and averaged them to form a mean cortical amyloid index.

\section{Genetic protocol}

A full description of the genetic protocol can be found in reference 31. In brief, saliva collection was conducted with Oragene kits (DNA Genotek, Ottawa, Ontario, Canada). Genetic analysis was performed at the University of Texas Southwestern Medical Center Microarray Core Facility. APOE status (rs429358 and rs7412) was acquired with TaqMan SNP Genotyping assays (Applied Biosystems, Foster City, CA).

\section{Data analysis approach}

To test our first hypothesis, that striatal nonheme iron content and global $A \beta$ burden would exhibit a positive association, we conducted a bivariate correlation. To assess the potential influence of age on this association, we ran the same correlation controlling for age. We also conducted several bivariate associations derived from the regional $A \beta$ SUVRs (medial frontal cortex, lateral temporal, lateral parietal, precuneus, and anterior and posterior cingulate) and iron content, as well as striatal SUVR (combined caudate and putamen) and iron content, to provide additional 
Figure 1 Representative images from all neuroimaging modalities
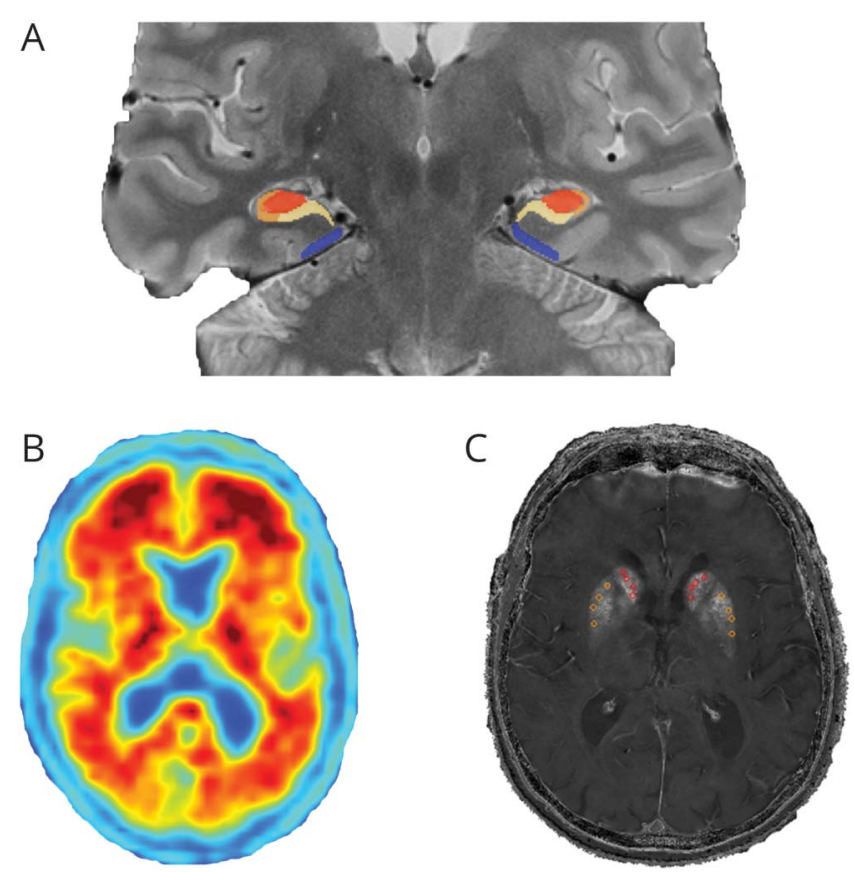

(A) Hippocampal subfields (cornu ammonis [CA]3/dentate gyrus in red, CA1/ 2 in orange, subiculum in yellow) and entorhinal cortex (blue) volumes derived from Automatic Segmentation of Hippocampal Subfields. (B) Amyvid PET scan for a cognitively normal participant with extensive $\beta$-amyloid burden. (C) Striatal nonheme iron content (R2*; seconds ${ }^{-1}$ ) image with manual probe placement in the caudate (red) and putamen (orange).

information about the potential associations between $A \beta$ and iron concentration.

To test our second hypothesis, that ERC volume, compared to 3 hippocampal subfield ROIs (subiculum, CA1/2, and CA3/ $\mathrm{DG})$, would be negatively associated with age, $A \beta$, and iron burden, we conducted a linear mixed-effects model implemented in R v3.5.3 (R Core Team, 2019, downloaded March $11,2019)$ using the LmerTest ${ }^{33}$ package and the Satterthwaite correction for degrees of freedom. Wald CIs were calculated with the confint command within $\mathrm{R}$. This model used meancentered age, SUVR, and striatal iron content as betweenparticipant factors; MTL ROI as a within-participant factor; and MTL ROI volume (mean-centered within each region) as the dependent variable, with a random effect of participant. Mean-centering independent variables allows proper estimation of lower-order effects, and because mean differences in volume were of no interest in the current analysis, we meancentered within each MTL ROI. A 4-way interaction (i.e., age $\times$ iron $\times$ SUVR $\times$ MTL ROI) and all subordinate 2- and 3-way interactions were included. Interactions were probed with simple effects or simple slopes estimates.

Outliers, or data points exhibiting potentially high leverage on the results, were assessed with 3 strategies. First, we implemented a conservative sensitivity analysis in which the top 5\% and bottom
$5 \%$ of residuals were removed from the analysis and the results recomputed. Second, we winsorized MTL volume within each ROI to 3 SDs and recomputed the results. Third, we conducted a robust mixed-effects model using robustlmm. ${ }^{34}$ Custom code was used to calculate Wald CIs for the robust model.

APOE genotype information was collected on most of the sample $(n=66)$. A secondary analysis was conducted covarying for the effects of dichotomous $A P O E \& 4$ status on the grand mean and regional volume by including $A P O E$ as a dichotomous factor (i.e., $\varepsilon 4-$ or $\varepsilon 4+$ ) along with its interaction with MTL ROI.

\section{Data availability}

Data can be made available on request.

\section{Results}

\section{Association between $A \beta$ and iron content}

The bivariate correlation between $\mathrm{A} \beta$ and striatal iron content was not significant $(r[68]=0.130, p=0.28)$ (figure 2$)$. This result was unchanged when controlling for age $(r[67]=-0.039$, $p=0.753$ ). To further explore potential associations between iron content and SUVR, we conducted correlations between measures in the regions used to calculate global SUVR, as well as an additional striatal region SUVR. There were no significant associations between iron content and SUVR in the lateral temporal $[r(68)=0.227,95 \% \mathrm{CI}-0.01$ to 0.44$]$, prefrontal $[r(68)=0.195,95 \% \mathrm{CI}-0.04$ to 0.41$]$, lateral parietal $[r(68)=$ $0.119,95 \% \mathrm{CI}-0.12$ to 0.34$]$, anterior cingulate $[r(68)=0.072$, $95 \% \mathrm{CI}-0.17$ to 0.30$]$, posterior cingulate $[r(68)=0.089,95 \%$ $\mathrm{CI}-0.14$ to 0.32$]$, or precuneus $[r(68)=0.066,95 \% \mathrm{CI}-0.17$ to 0.30 ] cortices or between striatal SUVR and iron content $[r(68)=0.055,95 \% \mathrm{CI}-0.18$ to 0.29$]$.

Figure 2 Association between R2* and amyloid SUVR

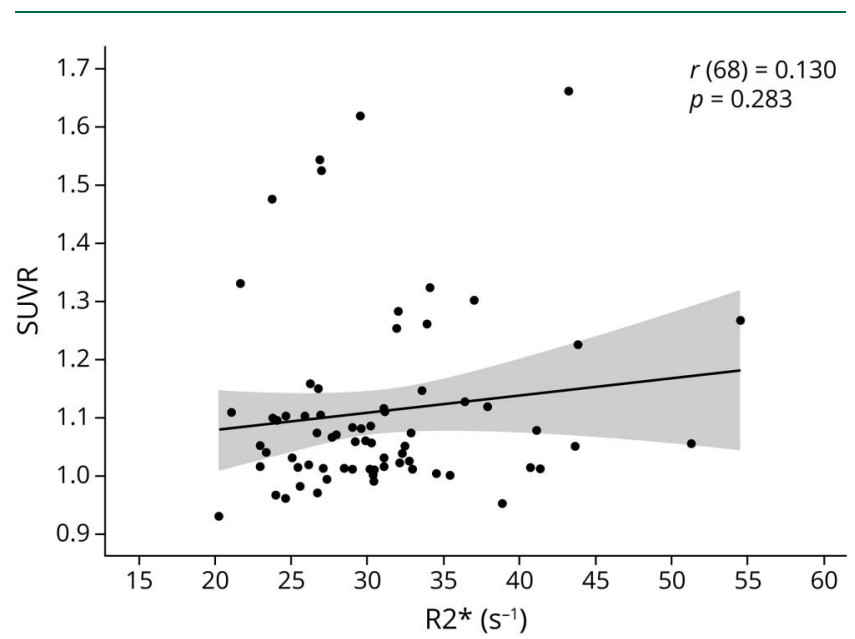

In the current sample of cognitively normal adults $>50$ years of age, there is no significant association between $\mathrm{R} 2{ }^{*}\left(\right.$ seconds $\left.^{-1}\right)$ (i.e., a measure of striatal iron content) and $\beta$-amyloid burden. SUVR = standardized uptake value ratio. 
Table 2 Bivariate correlations among variables of interest

\begin{tabular}{lllll}
\hline & ERC & Subiculum & CA1/2 & CA3/DG \\
\hline Age & $-0.143(-0.37$ to 0.10$)$ & $-0.213(-0.43 \text { to } 0.02)^{a}$ & $-0.042(-0.27$ to 0.19$)$ & $-0.173(-0.39$ to 0.07$)$ \\
\hline SUVR & $-0.179(-0.40$ to 0.06$)$ & $-0.112(-0.34$ to 0.13$)$ & $-0.113(-0.34$ to 0.12$)$ & $-0.206(-0.42 \text { to } 0.03)^{a}$ \\
\hline R2* & $-0.091(-0.32$ to 0.15$)$ & $-0.039(-0.27$ to 0.20$)$ & $-0.032(-0.27$ to 0.21$)$ & $-0.124(-0.35$ to 0.12$)$ \\
\hline
\end{tabular}

Abbreviations: $C A$ = cornu ammonis; $\mathrm{Dg}=$ dentate gyrus; $\mathrm{ERC}=$ entorhinal cortex; $\mathrm{R} 2^{*}=$ measure of striatal nonheme iron content; SUVR $=\beta$-amyloid standardized uptake value ratio.

Values represent zero-order correlations followed by the $95 \%$ confidence interval. Each correlation has $68 \mathrm{df}$. No bivariate correlations are significant. ${ }^{a} p<0.10$.

\section{Effects of $A \beta$, iron content, and age on MTL ROIs}

The results of the linear mixed-effects model indicated 1 significant 3-way interaction among SUVR, iron content, and MTL volume $\left(F_{3,186}=3.85, p=0.011\right)$. We refrained from probing this interaction because it was qualified by the presence of a significant 4-way interaction among age, iron content, SUVR, and MTL volume $\left(F_{3,186}=3.81, p=0.011\right)$. No other model $F$ tests were significant ( $p>0.141$ for all). Bivariate correlations among the predictor variables and MTL ROI volumes are presented in table 2. Full model results for conditional effects are presented in table 3.

We probed the 4-way interaction by testing the 3-way interaction (i.e., age $\times$ iron $\times$ SUVR) separately for each of the 4 MTL regions using the glht function from the multcomp ${ }^{35}$ package and a false discovery rate (FDR) correction $^{36}$ for the 7 post hoc effect and difference estimates. A significant interaction among age, SUVR, and iron content was detected for the ERC $\left(\beta=-3.34, z=-2.50, p-{ }_{F D R}=0.029\right)$, whereas no other MTL regions exhibited this effect: subiculum $(\beta=0.61$, $\left.z=0.46, p{ }^{-F D R}=0.711\right), \mathrm{CA} 1 / 2\left(\beta=-0.79, z=-0.59, p-{ }_{F D R}=\right.$ $0.711)$, and CA3/DG $(\beta=0.49, z=0.37, p-F D R=0.711)$. Furthermore, the interaction among age, SUVR, and iron content detected in the ERC was significantly stronger than the same 3-way interaction in all other hippocampal subfields: subiculum $\left(\beta=3.95, z=2.97, p^{-}{ }_{F D R}=0.013\right)$ and CA3/DG $(\beta$ $=3.83, z=2.88, p$-FDR $=0.014)$, except CA1 $/ 2(\beta=2.55, z=$ $1.92, p_{F D R}=0.097$; table 3 provides the CIs of differences).

To probe the 3-way interaction effect on the ERC, we used a simple slopes analysis to assess the nature of the relationship between age and volume at varying levels of iron and amyloid loads. The results indicated a significant positive relationship between age and ERC volume that roughly corresponded to amyloid SUVR levels $>1.15$ and iron content $<30 \mathrm{R}^{*} \mathrm{~s}^{-1}$ (figure 3 ). In addition, a significant negative relationship between age and ERC volume was present at values of amyloid SUVR $>1.15$ and iron values $>45 \mathrm{R}^{*} \mathrm{~s}^{-1}$ (figure 3).

\section{Supporting analyses}

To assess the potential influence of outliers on the results, we conducted 3 follow-up analyses: a sensitivity analysis, winsorization of the volumetric data to 3 SDs, and a robust mixed-effects model. The sensitivity analysis revealed a similar, albeit nonsignificant effect, for the 4-way interaction between age, SUVR, iron content, and MTL region $\left(F_{3,161.28}\right.$ $=2.38, p=0.072$ ), whereas the 4-way interaction remained significant in the winsorized analysis $\left(F_{3,186}=2.70\right.$, $p=0.047)$. The interaction among age, SUVR, and iron content in the ERC was again similar but nonsignificant in the sensitivity analysis $(\beta=-1.96, \mathrm{SE}=1.21,95 \% \mathrm{CI}-4.33$ to 0.42$)$ and the robust mixed-effects model $(\beta=-2.19, \mathrm{SE}=$ $1.24,95 \% \mathrm{CI}-4.62$ to 0.24$)$ but remained significant in the winsorized analysis $(\beta=-2.65, \mathrm{SE}=1.32,95 \% \mathrm{CI}-5.23$ to $-0.07)$. In each of these models, as was seen in the primary analysis, the age, SUVR, and iron content interaction in the ERC was significantly stronger compared to the subiculum - sensitivity analysis $(\beta=2.49, \mathrm{SE}=1.05,95 \% \mathrm{CI}$ $0.43-4.55)$, winsorized analysis $(\beta=3.26, \mathrm{SE}=1.31,95 \%$ CI $0.70-5.82)$, and robust analysis $(\beta=2.79, \mathrm{SE}=1.17,95 \%$ CI $0.51-5.08)$ - and CA3/DG - sensitivity analysis $(\beta=$ 2.26, $\mathrm{SE}=1.05,95 \% \mathrm{CI} 0.21-4.30)$, winsorized analysis $(\beta=$ $3.14, \mathrm{SE}=1.31,95 \% \mathrm{CI}[0.58-5.71])$, and robust analysis $(\beta=2.59, \mathrm{SE}=1.17,95 \%$ CI $0.31-4.87)$. Finally, we investigated residual normality in both the fixed-effect and random-effect components. In the full model, there were significant but small deviations from normality only in the fixed-effect residuals as evidenced by a Shapiro-Wilk test ( $W$ $=0.99, p=0.022)$. However, this is not the case in the sensitivity analysis $(W=0.99, p=0.269)$, and the primary findings were retained. Taken together, the pattern of findings is largely stable across several approaches used to investigate participants and data points with potentially high leverage on the results.

To test the potential influence of $A P O E$, a secondary analysis covarying for APOE $\varepsilon 4$ status was conducted. A set of results similar to those of the primary analysis was found, such that there was a significant 3-way interaction among MTL ROI, SUVR, and iron content $\left(F_{3,171}=4.76, p=0.003\right)$ and a significant 4-way interaction among MTL ROI, age, SUVR, and iron content $\left(F_{3,171}=4.24, p=0.006\right)$. No other effects were significant, and there was no effect of $A P O E$ on the grand mean volume $\left(F_{1,57}=0.28, p=0.596\right)$ or regional MTL volume $\left(F_{3,171}=1.68, p=0.174\right)$. The 3-way interaction among age, 
Table 3 Linear mixed-effects model results predicting MTL volumes

\begin{tabular}{|c|c|c|c|c|c|c|}
\hline Effect & Est. & SE & $d f$ & $t$ Value & $p$ Value & $95 \% \mathrm{Cl}$ \\
\hline Intercept (ERC) & -5.03 & 8.76 & 140.88 & -0.57 & 0.567 & -22.2 to 12.14 \\
\hline Age (ERC) & 0.38 & 0.89 & 140.88 & 0.43 & 0.667 & -1.36 to 2.13 \\
\hline SUVR (ERC) & -120.32 & 79.9 & 140.88 & -1.51 & 0.134 & -276.91 to 36.27 \\
\hline $\mathrm{R}^{2 *}(\mathrm{ERC})$ & 1.74 & 1.56 & 140.88 & 1.11 & 0.268 & -1.32 to 4.79 \\
\hline $\mathrm{CA} 1 / 2$ & 4.89 & 8.73 & 186 & 0.56 & 0.576 & -12.22 to 22.01 \\
\hline CA3/DG & 3.25 & 8.73 & 186 & 0.37 & 0.711 & -13.87 to 20.36 \\
\hline Sub & 2.13 & 8.73 & 186 & 0.24 & 0.807 & -14.98 to 19.25 \\
\hline Age $\times$ SUVR (ERC) & 14.68 & 8.78 & 140.88 & 1.67 & 0.097 & -2.52 to 31.88 \\
\hline Age $\times$ R2* $(E R C)$ & -0.32 & 0.16 & 140.88 & -2 & 0.048 & -0.63 to -0.01 \\
\hline$S U V R \times R 2 *(E R C)$ & 37.27 & 13.58 & 140.88 & 2.75 & 0.007 & 10.66 to 63.88 \\
\hline Age $\times$ CA $1 / 2$ & -0.37 & 0.89 & 186 & -0.41 & 0.68 & -2.11 to 1.37 \\
\hline Age $\times$ CA3/DG & -0.58 & 0.89 & 186 & -0.66 & 0.513 & -2.32 to 1.16 \\
\hline Age $\times$ Sub & -1.22 & 0.89 & 186 & -1.37 & 0.171 & -2.96 to 0.52 \\
\hline SUVR $\times$ CA1/2 & 116.95 & 79.62 & 186 & 1.47 & 0.144 & -39.1 to 273 \\
\hline SUVR $\times$ CA3/DG & -16.53 & 79.62 & 186 & -0.21 & 0.836 & -172.58 to 139.53 \\
\hline SUVR $\times$ Sub & 3.67 & 79.62 & 186 & 0.05 & 0.963 & -152.39 to 159.72 \\
\hline $\mathrm{R}^{*} * \mathrm{CA} 1 / 2$ & -1.5 & 1.56 & 186 & -0.97 & 0.336 & -4.55 to 1.55 \\
\hline$R 2 * \times C A 3 / D G$ & -2.26 & 1.56 & 186 & -1.45 & 0.148 & -5.31 to 0.79 \\
\hline$R 2 * \times$ Sub & -1.45 & 1.56 & 186 & -0.93 & 0.352 & -4.5 to 1.6 \\
\hline Age $\times$ SUVR $\times$ R2* $(E R C)$ & -3.34 & 1.33 & 140.88 & -2.5 & 0.013 & -5.95 to -0.72 \\
\hline Age $\times$ SUVR $\times$ CA1/2 & -16.63 & 8.75 & 186 & -1.9 & 0.059 & -33.77 to 0.51 \\
\hline Age $\times$ SUVR $\times$ CA3/DG & -4.11 & 8.75 & 186 & -0.47 & 0.639 & -21.25 to 13.03 \\
\hline Age $\times$ SUVR $\times$ Sub & -1.49 & 8.75 & 186 & -0.17 & 0.865 & -18.63 to 15.65 \\
\hline Age $\times \mathrm{R}^{*} \times \mathrm{CA} 1 / 2$ & 0.32 & 0.16 & 186 & 2.02 & 0.045 & 0.01 to 0.63 \\
\hline Age $\times \mathrm{R}^{*} \times \mathrm{CA} 3 / \mathrm{DG}$ & 0.16 & 0.16 & 186 & 1.05 & 0.297 & -0.14 to 0.47 \\
\hline Age $\times R 2 * \times$ Sub & 0.14 & 0.16 & 186 & 0.87 & 0.385 & -0.17 to 0.45 \\
\hline SUVR $\times R 2 * \times C A 1 / 2$ & -27.97 & 13.53 & 186 & -2.07 & 0.04 & -54.49 to -1.45 \\
\hline SUVR $\times R_{2} *$ CA3/DG & -40.99 & 13.53 & 186 & -3.03 & 0.003 & -67.51 to -14.47 \\
\hline SUVR $\times R_{2} * \times$ Sub & -38.44 & 13.53 & 186 & -2.84 & 0.005 & -64.96 to -11.92 \\
\hline Age $\times$ SUVR $\times$ R2* $\times$ CA1/2 & 2.55 & 1.33 & 186 & 1.92 & 0.057 & -0.06 to 5.15 \\
\hline Age $\times$ SUVR $\times$ R2* $\times$ CA3/DG & 3.83 & 1.33 & 186 & 2.88 & 0.004 & 1.23 to 6.43 \\
\hline Age $\times$ SUVR $\times$ R2* $\times$ Sub & 3.95 & 1.33 & 186 & 2.97 & 0.003 & 1.35 to 6.55 \\
\hline
\end{tabular}

Abbreviations: $\mathrm{CA}=$ cornu ammonis; $\mathrm{Cl}$ = confidence interval; $\mathrm{DG}=$ dentate gyrus; $\mathrm{ERC}=$ entorhinal cortex; Est. = estimate; $\mathrm{MTL}=$ medial temporal lobe; $\mathrm{R} 2 *$ = measure of striatal nonheme iron content; SE = standard error; Sub = subiculum; SUVR = $\beta$-amyloid standardized uptake value ratio.

All variables mean-centered. MTL volumes (mean-centered within each region of interest) were the dependent variable. Wald $95 \%$ CIs are presented for each estimated effect. The ERC is the reference region. A random effect for participant was included in the model.

SUVR, and iron content in the ERC was significant $(\beta=-1.99$, $\mathrm{SE}=0.68,95 \% \mathrm{CI}-3.31$ to -0.67$)$ and, in this case, greater compared to the effect in the subiculum $(\beta=2.16, \mathrm{SE}=0.68$,
95\% CI $0.83-3.49), \mathrm{CAl} / 2(\beta=1.61, \mathrm{SE}=0.68,95 \% \mathrm{CI}$ $0.66-3.31)$, and $\mathrm{CA} 3 / \mathrm{DG}(\beta=1.99, \mathrm{SE}=0.68,95 \% \mathrm{CI}$ $0.28-2.94)$. 
Figure 3 Slope of age and ERC volume as a function of $A \beta$ SUVR and striatal iron

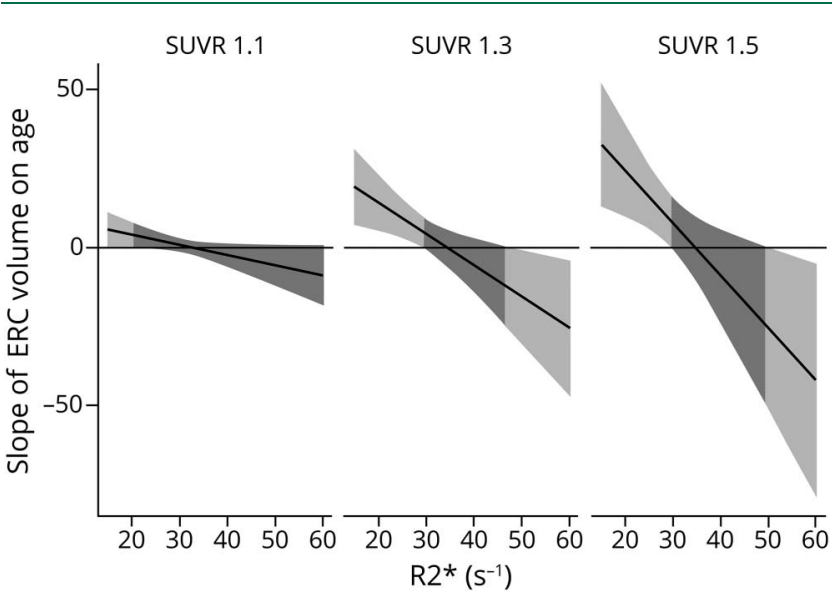

The 4-way interaction is displayed as model-implied simple slopes of age predicting entorhinal cortex (ERC) volume as a function of iron concentration ( $R 2^{*}$ ) at 3 levels of $\beta$-amyloid $(A \beta)$ corresponding a standardized uptake value ratio (SUVR) of 1.1, 1.3, and 1.5, levels that correspond to increasing and clinically relevant levels of $A \beta$. At levels of $A \beta$ SUVR $<\approx 1.15$, there are no independent relation between age and ERC volume and no interaction with iron concentration. At levels of $A \beta$ SUVR $\geq 1.15$, there is an association between age and ERC volume, and the magnitude (and direction) of effect depends on iron concentration. For individuals with high iron concentration (roughly $>45$ seconds $^{-1}$ ) and high $A \beta$, there is a significant negative association between age and ERC volume (right side of light gray shading in middle and right panels) that strengthens as $A \beta$ and iron increase. For individuals with low iron (roughly $<30$ seconds $^{-1}$ ) and high $A \beta$, there is a significant positive association between age and ERC volume (left side of light gray shading in middle and right panels) that strengthens with less iron and greater $A \beta$.

\section{Discussion}

The current in vivo study investigated the potential combined effect of global $A \beta$ deposition and striatal iron concentrationproxy measures for $\mathrm{AD}$ pathology and oxidative stress-on agerelated differences in hippocampal subfield and ERC volumes in a sample of cognitively normal adults. In line with our hypotheses, results indicated an interactive effect of $A \beta$, iron content, and age on ERC volume specifically, whereas a negative association between age and ERC volume was present only in individuals with both elevated iron and elevated $A \beta$ loads. Overall, the results suggest that iron concentration may work in synergy with $A \beta$ to affect the structural integrity of a key region of the MTL, the ERC, which is altered early in the $\mathrm{AD}$ pathologic cascade.

In individuals with elevated $A \beta$, age-related differences in ERC volume were dependent on brain iron concentration. Age was positively correlated with ERC volume in individuals with relatively low iron concentration $\left(\mathrm{R} 2^{*}<30 \mathrm{~s}^{-1}\right)$, whereas age was negatively correlated with ERC volume in individuals with relatively high iron concentration $\left(\mathrm{R} 2{ }^{*}>45 \mathrm{~s}^{-1}\right)$. Consistent with the hypothesized synergistic effect, the association strengthened following a continuum as both $A \beta$ and iron concentration increased. According to hypothesized models, ${ }^{23,37,38}$ smaller ERC volume in older age with these elevated biomarkers is likely driven by the deleterious effects of oxidative stress and chronic inflammation on neurons, myelin, and other surrounding tissue. Furthermore,
$\mathrm{A} \beta$ oligomers form around a core of iron, and these oligomers are associated with the production of hydrogen peroxide, which is proapoptotic and cytotoxic. ${ }^{5,9}$ The bidirectional relation between $\mathrm{A} \beta$ and iron dyshomeostasis, further exacerbated by feedback loops involving oxidative stress and proinflammatory cytokines, accelerates the deleterious cycle that may lead to neuronal damage and eventually cell death, as well as the release of more iron from damaged, iron-rich oligodendrocytes. ${ }^{5,39}$ In addition, the anatomic cascade of $\mathrm{AD}$ begins in the perirhinal cortex (including ERC) and typically, after the onset of cognitive symptoms, moves into inferior temporal and hippocampal regions. ${ }^{11}$ In our sample of cognitively normal individuals, these associations not only were limited to the ERC but also were significantly weaker and close to zero in the hippocampal subfield regions. The lack of independent effects of $A \beta$ or iron content on any region also highlights that the interplay between these measures is critical to elucidating their impact on the brain.

A prior report from our group indexed lifespan age differences in iron concentration in the ERC, and greater iron concentration partially explained smaller regional volumes among older adults but not middle-aged and younger adults. ${ }^{40}$ The current report is consistent with this observation and extends it to account for elevated risk for $\mathrm{AD}$ indicated by high $\mathrm{A} \beta$. The resource-intensive and iron-dependent myelination processes that mark protracted development of ERC late into the lifespan ${ }^{39}$ may make the region particularly prone to oxidative stress, inflammation, and amyloid deposition. Although both $\mathrm{A} \beta$ and iron concentrations are critical to normal cell function, ${ }^{23,39}$ it is the paradox of $\mathrm{AD}$ that excessive accumulation of either may initiate a neurodegenerative cascade. Indeed, the reported evidence is consistent with histologic and animal studies that suggest that $A \beta$ acts synergistically with dysregulated iron and may result in $A \beta$ oligomers and plaques and oxidative stress. $^{5,9,41}$

It is important to note that the combined effects of $A \beta$ and iron content on the association between age and ERC volume were limited to individuals with $A \beta$ levels roughly $>1.15$, a value above the recommended clinical cutoff for florbetapir positivity of 1.11. ${ }^{42}$ Thus, in the range of iron values measured in the current study, iron in the absence of clinically elevated $A \beta$ was not associated with age-related volume differences in the ERC. It is likely that there are significant individual differences in susceptibility and response to oxidative stress. Either individuals without significant $A \beta$ burden but who exhibit high levels of iron may be resilient to elevated levels of iron, or there may exist another mechanism that prevents iron from triggering the creation of $A \beta$.

The hypothesized effect was observed on a continuum that also included a positive association between age and ERC volume in individuals with elevated $A \beta$ but low iron content, which was unexpected. Protracted development and maintenance of ERC is consistent with nonpathologic aging. ${ }^{14,43}$ Iron is necessary for neuronal function, but its accumulation within age-sensitive regions is an antecedent to metabolic dysfunction, oxidative stress, chronic inflammation, and cell death. ${ }^{7,8}$ The consequences of iron accumulation are observed across the adult lifespan as 
neuronal dysfunction indicated by $\mathrm{fMRI},{ }^{44,45}$ regional brain shrinkage, ${ }^{20,46}$ and cognitive decline. ${ }^{19,20}$ Therefore, nonheme iron homeostasis is of the utmost priority to maintain brain health and function. Because $A \beta$ binds soluble nonheme iron in the extracellular space, ${ }^{3,41}$ it is plausible that $A \beta$ may help to prevent iron-related oxidative stress and to promote maintenance of ERC volume. Indeed, a previous study has reported positive associations between $A \beta$ and MTL volume, including the hippocampus and surrounding cortex, ${ }^{47}$ and $\approx 20 \%$ to $30 \%$ of cognitively normal individuals have significant $A \beta$ burden. ${ }^{1,30}$ Taken together, these findings suggest that $A \beta$ is not solely degenerative and that its association with pathology may depend on other biological factors, including iron concentration. In this manner, evidence of high iron concentration and high $A \beta$ may indicate a distressed system that cannot sufficiently regulate and is at risk for accumulation of $\mathrm{AD}$-related pathology.

$\mathrm{AD}$ is thought to be associated with a physiologic cascade in which deleterious processes occur in a specific order. The current study provides evidence that in cognitively normal adults, iron and $A \beta$ exhibit a synergistic effect across older age on ERC volume; however, it will be critical for future research to investigate these processes longitudinally. Despite hypotheses of synergism between $A \beta$ and iron accumulation across the lifespan, it is not clear on what time scales these antecedent processes may occur or whether some individuals may be more or less resistant to oxidative stress and chronic inflammation. Although we hypothesized that these effects would more likely appear in the ERC — namely due to its volumetric preservation in healthy aging and early sensitivity to $\mathrm{AD}$ pathologycompared to the hippocampus, it is possible that longitudinal studies would be better suited to separate the effects of $\mathrm{AD}$ pathology-associated volumetric decline from age-related change. The ERC is thought to be among the earliest sites of $\mathrm{AD}$ pathology. However, the hippocampus is also known to be associated with $\mathrm{AD}$ pathology early in the disease. ${ }^{11}$ Thus, the cross-sectional nature of the current study may contribute to the lack of synergistic effects of $A \beta$ and iron content within the hippocampus. In addition, the current study used reliable, wellvalidated approaches to measure both striatal iron and global $A \beta$ across the cortex. Future research will be needed to investigate potential local associations of iron and $A \beta$ concentrations within the MTL regions in the context of $\mathrm{AD}$ pathology.

A key limitation in the current study was the lack of tau measurements in our sample. While the literature suggests a specific role for iron in the accumulation of $A \beta$ oligomers, iron is also thought to play a role in the formation of $\mathrm{tau}^{48}$ and there is evidence for an association between iron and tau in the clinical stages of $\mathrm{AD} .^{49}$ In the current investigation, we find detrimental effects of age on ERC volume only in those with both elevated iron and $A \beta$, not in those with elevated $A \beta$ alone. Because a significant portion of cognitively normal adults will present with elevated levels of $A \beta$ and exhibit tau pathology, iron homeostasis may be a critical factor in elucidating processes that provide cognitive resiliency for some individuals despite $A \beta$ and tau accumulation. Iron concentration may also shed light on why some individuals accumulate significant tau without $A \beta$ burden. It will be important for future research to investigate iron in the context of $A \beta$, tau, and cognition to better understand the complex processes underlying neural degeneration. In addition, while the current study investigated nonheme brain iron, other metals (e.g., copper and zinc) also play a role in oxidative stress, specifically in conjunction with $\mathrm{A} \beta \mathrm{s}^{5,41}$ Therefore, iron presents as just 1 target for future investigations aiming to understand the myriad factors associated with increased risk for $\mathrm{AD}$.

Prevailing models of $A D$ suggest that elevated $A \beta$ is one of the earliest measurable $\mathrm{AD}$ biomarkers, followed by tau accumulation and MTL atrophy. ${ }^{2}$ Each of these events in the cascade occurs before the onset of cognitive symptoms, highlighting the need to investigate factors associated with an increased risk for $\mathrm{AD}$ in cognitively normal samples. The present study finds that iron and $A \beta$ act synergistically, indicating that a negative association between age and MTL volume is present only in the ERC and in individuals with elevated levels of iron and $A \beta$. These findings highlight the potential role for iron as an important contributor to the earliest, preclinical stages of pathologic aging.

\section{Acknowledgment}

The authors thank Marci Horn and David Hoagey for assistance with PET image processing.

\section{Study funding}

This study was sponsored in part by an Investigator Initiated Trial grant from Eli Lilly and Company for the Amyvid ligand, support from BvB Dallas and AWARE, and grants from the NIH (AG036848, AG036818, AG057537), and Alzheimer's Association NIRG-397220.

\section{Disclosure}

The authors report no disclosures relevant to the manuscript. Go to Neurology.org/N for full disclosures.

\section{Publication history}

Received by Neurology December 29, 2019. Accepted in final form June 26, 2020.

\begin{tabular}{|c|c|c|}
\hline Name & Location & Contribution \\
\hline $\begin{array}{l}\text { Chris M. } \\
\text { Foster, PhD }\end{array}$ & $\begin{array}{l}\text { University of Texas at } \\
\text { Dallas, School of Brain and } \\
\text { Behavioral Sciences, Center } \\
\text { for Vital Longevity }\end{array}$ & $\begin{array}{l}\text { Processed T2/PD-weighted } \\
\text { images; drafted the } \\
\text { manuscript for intellectual } \\
\text { content; analyzed and } \\
\text { interpreted the data; } \\
\text { performed statistical } \\
\text { analysis }\end{array}$ \\
\hline $\begin{array}{l}\text { Kristen M. } \\
\text { Kennedy, } \\
\text { PhD }\end{array}$ & $\begin{array}{l}\text { University of Texas at } \\
\text { Dallas, School of Brain and } \\
\text { Behavioral Sciences, Center } \\
\text { for Vital Longevity }\end{array}$ & $\begin{array}{l}\text { Designed and } \\
\text { conceptualized the study; } \\
\text { revised the manuscript for } \\
\text { intellectual content; } \\
\text { interpreted the data }\end{array}$ \\
\hline
\end{tabular}


Appendix (continued)

\begin{tabular}{lll}
\hline Name & Location & Contribution \\
\hline $\begin{array}{l}\text { Ana M. } \\
\text { Daugherty, } \\
\text { PhD }\end{array}$ & $\begin{array}{l}\text { Wayne State University, } \\
\text { Department of Psychology, } \\
\text { Department of Psychiatry } \\
\text { and Behavioral } \\
\text { Neurosciences, Institute of } \\
\text { Gerontology, Detroit, Ml }\end{array}$ & $\begin{array}{l}\text { Processed the R2* images; } \\
\text { revised the manuscript for } \\
\text { intellectual content }\end{array}$ \\
\hline $\begin{array}{l}\text { Karen M. } \\
\text { Rodrigue, } \\
\text { PhD }\end{array}$ & $\begin{array}{l}\text { University of Texas at } \\
\text { Dallas, School of Brain and } \\
\text { Behavioral Sciences, Center } \\
\text { for Vital Longevity }\end{array}$ & $\begin{array}{l}\text { Designed and } \\
\text { conceptualized the study; } \\
\text { revised the manuscript for } \\
\text { intellectual content; } \\
\text { interpreted the data }\end{array}$ \\
\hline
\end{tabular}

\section{References}

1. Jansen WJ, Ossenkoppele R, Knol DL, et al. Prevalence of cerebral amyloid pathology in persons without dementia: a meta-analysis. JAMA 2015;313:1924-1938.

2. Jack CR, Knopman DS, Jagust WJ, et al. Tracking pathophysiological processes in Alzheimer's disease: an updated hypothetical model of dynamic biomarkers. Lancet Neurol 2013;12:207-216.

3. Chen G, Xu T, Yan Y, et al. Amyloid beta: structure, biology and structure-based therapeutic development. Acta Pharmacol Sin 2017;38:1205-1235.

4. Selkoe DJ, Hardy J. The amyloid hypothesis of Alzheimer's disease at 25 years. EMBO Mol Med 2016;8:595-608.

5. Lynch T, Cherny RA, Bush AI. Oxidative processes in Alzheimer's disease: the role of A $\beta$-metal interactions. Exp Gerontol 2000;35:445-451.

6. Morris G, Berk M, Carvalho AF, Maes M, Walker AJ, Puri BK. Why should neuroscientists worry about iron? The emerging role of ferroptosis in the pathophysiology of neuroprogressive diseases. Behav Brain Res 2018;341:154-175.

7. Ward RJ, Zucca FA, Duyn JH, Crichton RR, Zecca L. The role of iron in brain ageing and neurodegenerative disorders. Lancet Neurol 2014;13:1045-1060.

8. Zecca L, Youdim MBH, Riederer P, Connor JR, Crichton RR. Iron, brain ageing and neurodegenerative disorders. Nat Rev Neurosci 2004;5:863-873.

9. Plascencia-Villa G, Ponce A, Collingwood JF, et al. High-resolution analytical imaging and electron holography of magnetite particles in amyloid cores of Alzheimer's disease. Sci Rep 2016;6:24873.

10. Ayton S, Wang Y, Diouf I, et al. Brain iron is associated with accelerated cognitive decline in people with Alzheimer pathology. Mol Psychiatry Epub 2019 Feb 18.

11. Braak H, Braak E. Frequency of stages of Alzheimer-related lesions in different age categories. Neurobiol Aging 1997;18:351-357.

12. Van Hoesen GW. The human parahippocampal region in Alzheimer's disease, dementia, and ageing. In: The Parahippocampal Region: Organization and Role in Cognitive Function. Oxford: Oxford University Press; 2002:270-295.

13. Raz N, Rodrigue KM, Head D, Kennedy KM, Acker JD. Differential aging of the medial temporal lobe: a study of a five-year change. Neurology 2004;62:433-438.

14. Hasan KM, Mwangi B, Cao B, et al. Entorhinal cortex thickness across the human lifespan. J Neuroimaging 2016;26:278-282.

15. Rodrigue KM, Raz N. Shrinkage of the entorhinal cortex over five years predicts memory performance in healthy adults. J Neurosci 2004;24:956-963.

16. Killiany RJ, Hyman BT, Gomez-Isla T, et al. MRI measures of entorhinal cortex vs hippocampus in preclinical AD. Neurology 2002;58:1188-1196.

17. Folstein MF, Folstein SE, McHugh PR. "Mini-Mental State:" a practical method for grading the cognitive state of patients for the clinician. J Psychiatr Res 1975;12:189-198.

18. Radloff LS. A self-report depression scale for research in the general population. Appl Psychol Meas 1977;1:385-401.

19. Daugherty AM, Hoagey DA, Kennedy KM, Rodrigue KM. Genetic predisposition for inflammation exacerbates effects of striatal iron content on cognitive switching ability in healthy aging. Neuroimage 2019;185:471-478.

20. Rodrigue KM, Daugherty AM, Haacke EM, Raz N. The role of hippocampal iron concentration and hippocampal volume in age-related differences in memory. Cereb Cortex 2013;23:1533-1541.
21. Shrout PE, Fleiss JL. Intraclass correlations: uses in assessing rater reliability. Psychol Bull 1979;86:420-428

22. Daugherty AM, Raz N. Appraising the role of iron in brain aging and cognition promises and limitations of MRI methods. Neuropsychol Rev 2015;25:272-287.

23. Raz N, Daugherty AM. Pathways to brain aging and their modifiers: Free-RadicalInduced Energetic and Neural Decline in Senescence (FRIENDS) model—a minireview. Gerontology 2018;64:49-57.

24. Foster CM, Kennedy KM, Hoagey DA, Rodrigue KM. The role of hippocampal subfield volume and fornix microstructure in episodic memory across the lifespan. Hippocampus 2019;29:1206-1223.

25. Wisse LEM, Daugherty AM, Olsen RK, et al. A harmonized segmentation protocol for hippocampal and parahippocampal subregions: why do we need one and what are the key goals? Hippocampus 2017;27:3-11.

26. Yushkevich PA, Pluta JB, Wang H, et al. Automated volumetry and regional thickness analysis of hippocampal subfields and medial temporal cortical structures in mild cognitive impairment. Hum Brain Mapp 2015;36:258-287.

27. Raz N, Lindenberger U, Rodrigue KM, et al. Regional brain changes in aging healthy adults: general trends, individual differences and modifiers. Cereb Cortex 2005;15:1676-1689.

28. Avants BB, Tustison NJ, Song G, Gee JC. ANTS: Advanced Open-Source Normalization Tools for Neuroanatomy. Philadelphia: Penn Image Computing and Science Laboratory; 2009

29. Fischl B. FreeSurfer. Neuroimage 2012;62:774-781.

30. Rodrigue KM, Kennedy KM, Devous MD, et al. $\beta$-Amyloid burden in healthy aging: regional distribution and cognitive consequences. Neurology 2012;78:387-395.

31. Kennedy KM, Reese ED, Horn MM, et al. BDNF val66met polymorphism affects aging of multiple types of memory. Brain Res 2015;1612:104-117.

32. R Core Team. R: A Language and Environment for Statistical Computing. Vienna: R Foundation for Statistical Computing; 2019.

33. Kuznetsova A, Brockhoff PB, Christensen RHB. ImerTest package: tests in linear mixed effects models. J Stat Softw 2017;82.

34. Koller M. robustlmm: An R package for robust estimation of linear mixed-effects models. J Stat Softw 2016;75.

35. Hothorn T, Bretz F, Westfall P. Simultaneous inference in general parametric models. Biom J 2008;50:346-363.

36. Benjamini Y, Hochberg Y. Controlling the false discovery rate: a practical and powerful approach to multiple testing. J R Stat Soc Ser B 1995;57:289-300.

37. Bartzokis G. Alzheimer's disease as homeostatic responses to age-related myelin breakdown. Neurobiol Aging 2011;32:1341-1371.

38. Liu JL, Fan YG, Yang ZS, Wang ZY, Guo C. Iron and Alzheimer's disease: from pathogenesis to therapeutic implications. Front Neurosci 2018;12:632.

39. Bartzokis G. Age-related myelin breakdown: a developmental model of cognitive decline and Alzheimer's disease. Neurobiol Aging 2004;25:5-18.

40. Rodrigue KM, Haacke EM, Raz N. Differential effects of age and history of hypertension on regional brain volumes and iron. Neuroimage 2011;54:750-759.

41. Maynard CJ, Cappai R, Volitakis I, et al. Overexpression of Alzheimer's disease amyloid- $\beta$ opposes the age-dependent elevations of brain copper and iron. J Bio Chem 2002;277:44670-44676.

42. Clark CM, Schneider JA, Bedell BJ, et al. Use of florbetapir-PET for imaging $\beta$-amyloid pathology. JAMA 2011;305:275-283.

43. Graterón L, Insausti AM, García-Bragado F, et al. Postnatal development of the human entorhinal cortex. In: The Parahippocampal Region: Organization and Role in Cognitive Function. Oxford: Oxford University Press; 2002:20-31.

44. Kalpouzos G, Garzón B, Sitnikov R, et al. Higher striatal iron concentration is linked to frontostriatal underactivation and poorer memory in normal aging. Cereb Cortex 2017;27:3427-3436.

45. Salami A, Avelar-Pereira B, Garzón B, Sitnikov R, Kalpouzos G. Functional coherence of striatal resting-state networks is modulated by striatal iron content. Neuroimage 2018; 183:495-503.

46. Daugherty AM, Haacke EM, Raz N. Striatal iron content predicts its shrinkage and changes in verbal working memory after two years in healthy adults. J Neurosci 2015 35:6731-6743.

47. Chételat G, Villemagne VL, Pike KE, et al. Larger temporal volume in elderly with high versus low beta-amyloid deposition. Brain 2010;133:3349-3358.

48. Masaldan S, Bush AI, Devos D, Rolland AS, Moreau C. Striking while the iron is hot: iron metabolism and ferroptosis in neurodegeneration. Free Radic Biol Med Elsevier B.V 2019;133:221-233.

49. van Duijn S, Bulk M, van Duinen SG, et al. Cortical iron reflects severity of Alzheimer's disease. J Alzheimers Dis 2017;60:1533-1545. 


\section{Neurology}

\section{Contribution of iron and $A \beta$ to age differences in entorhinal and hippocampal subfield volume}

Chris M. Foster, Kristen M. Kennedy, Ana M. Daugherty, et al.

Neurology 2020;95;e2586-e2594 Published Online before print September 16, 2020

DOI 10.1212/WNL.0000000000010868

This information is current as of September 16, 2020

\section{Updated Information \&} Services

References

Citations

Subspecialty Collections

Permissions \& Licensing

Reprints including high resolution figures, can be found at: http://n.neurology.org/content/95/18/e2586.full

This article cites 42 articles, 7 of which you can access for free at: http://n.neurology.org/content/95/18/e2586.full\#ref-list-1

This article has been cited by 1 HighWire-hosted articles: http://n.neurology.org/content/95/18/e2586.full\#\#otherarticles

This article, along with others on similar topics, appears in the following collection(s):

\section{Volumetric MRI}

http://n.neurology.org/cgi/collection/volumetric_mri

Information about reproducing this article in parts (figures,tables) or in its entirety can be found online at:

http://www.neurology.org/about/about_the_journal\#permissions

Information about ordering reprints can be found online:

http://n.neurology.org/subscribers/advertise

Neurology ${ }^{\circledR}$ is the official journal of the American Academy of Neurology. Published continuously since 1951, it is now a weekly with 48 issues per year. Copyright Copyright ( 2020 The Author(s). Published by Wolters Kluwer Health, Inc. on behalf of the American Academy of Neurology.. All rights reserved. Print ISSN: 0028-3878. Online ISSN: 1526-632X.

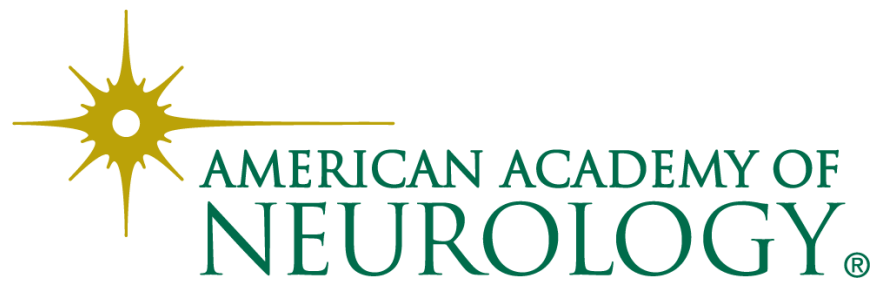

